\title{
Measurement of Gastric Circumference in Foetuses with Oesophageal Atresia
}

\author{
Messung des Magenumfangs bei Feten mit Ösophagusatresie
}

Authors

Affiliations
M. Hoopmann ${ }^{1}$, K. O. Kagan ${ }^{1}$, F. Borgmeier ${ }^{1}$, G. Seitz ${ }^{2}$, J. Arand ${ }^{3}$, P. Wagner

${ }^{1}$ Department of Obstetrics and Gynecology, University of Tübingen, Tübingen

2 Department of Pediatric Surgery and Urology, University Children's Hospital, Tübingen

${ }^{3}$ Department of Neonatology, University Children's Hospital, Tübingen
Key words
- gastric circumference
- oesophageal atresia
- tracheo-oesophageal fistula
Schlüsselwörter
- Magenumfang
- Ösophagusatresie
- tracheoösophageale Fistel

Deutsche Version unter: www.thieme-connect.de/ ejournals/gebfra

\section{received 18.7 .2015 \\ revised 23.8.2015 \\ accepted $\quad 25.8 .2015$}

Bibliography

DOI http://dx.doi.org/

10.1055/s-0035-1558172

Geburtsh Frauenheilk 2015; 75 :

1148-1152 @ Georg Thieme

Verlag KG Stuttgart · New York . ISSN 0016-5751

\section{Correspondence}

\section{PD Dr. Markus Hoopmann}

University of Tübingen

Department of Obstetrics

and Gynecology

Calwer Straße 7

72076 Tübingen

MHoopmann@gmx.de

\section{Abstract \\ $\nabla$}

Background: The specific recognition of oesophageal atresia $(\mathrm{OA})$ with or without a tracheal fistula in a foetus is a diagnostic challenge for prenatal medicine. The aim of the present work is to analyse the value of the measurement of gastric size in the diagnosis of this significant malformation. Materials and Methods: Altogether, the examinations of 433 pregnancies between the 18.4 and 39.1 weeks of gestation were retrospectively analysed. 59 of these foetuses exhibited an OA. By means of a linear regression analysis with normal foetuses, significant parameters influencing gastric size were examined. Subsequently the gastric sizes were transformed into $\mathrm{z}$ values and a comparison was made between $\mathrm{OA}$ with and without fistulae with the help of $t$ tests.

Results: In the normal foetuses there was a significant association between the gastric circumference and the abdominal circumference (circumference $=6.809+0.179 \times$ abdominal circumference, $r=0.686, p<0.0001)$. In the normal group the average was 43.0 (standard deviation [SD] 13.7) $\mathrm{mm}$ and those in foetuses with and without fistuale were 33.8 (SD 22.7) and 0.9 (SD 3.7) mm. In 34 (57.6\%) foetuses with an OA, the gastric circumference was below the 5th percentile. In detail, there were 13 (34.2\%) foetuses with a fistula and $21(100 \%)$ without a fistula. The average $z$ values in the normal group and in the groups of $\mathrm{OA}$ with fistula and without fistula amounted to 0.0 (SD 1.0), -1.3 (SD 2.2) and -4.5 (SD 1.0).

Conclusion: Measurements of the gastric circumference below the 5th percentile should lead to further diagnostic measures, especially when associated with polyhydramnios. Although $\mathrm{OA}$ without a fistula is always conspicuous, only about one in three OAs with fistula are associated with a significantly smaller stomach.

\section{Zusammenfassung \\ $\nabla$}

Fragestellung: Die gezielte Erkennung einer fetalen Ösophagusatresie (ÖA) mit oder ohne tracheale Fisteln stellt eine diagnostische Herausforderung für die Pränatalmedizin dar. Ziel der vorliegenden Arbeit war es, den Stellenwert der Messung des Magenumfangs für die Diagnostik dieser bedeutsamen Fehlbildung zu analysieren.

Material und Methodik: Insgesamt wurden die Untersuchungen von 433 Schwangerschaften zwischen der 18,4 bis 39,1 Schwangerschaftswoche retrospektiv ausgewertet. 59 dieser Feten wiesen eine ÖA auf. Mittels linearer Regressionsanalyse wurden bei normalen Feten signifikante Einflussparameter auf den Magenumfang untersucht. Anschließend erfolgte die Umwandlung der Magenumfänge in z-Werte und der Vergleich zwischen den ÖA mit und ohne Fistel mit der Normalpopulation mithilfe eines t-Tests.

Ergebnisse: Bei den normalen Feten zeigte sich eine signifikante Assoziation zwischen dem Umfang des Magens und dem Abdomenumfang (Umfang $=6,809+0,179 \times$ Abdomenumfang, $r=0,686$, $\mathrm{p}<0,0001)$. Der mittlere Magenumfang lag in der normalen Gruppe bei 43,0 (Standardabweichung [STW] 13,7) mm und bei Feten mit und ohne Fistel bei 33,8 (STW 22,7) und 0,9 (STW 3,7) mm. Bei $34(57,6 \%)$ Feten mit einer ÖA lag der Magenumfang < 5er-Perzentile. Im Einzelnen waren es 13 (34,2\%) Feten mit einer Fistel und 21 (100\%) ohne Fistel. Die mittleren z-Werte in der normalen Gruppe und in der Gruppe der ÖA mit Fistel und ohne Fistel lagen bei 0,0 (STW 1,0), -1,3 (STW 2,2 ) und $-4,5$ (STW 1,0).

Schlussfolgerung: Messungen des Magenumfangs < 5er-Perzentile sollten eine weiterführende Diagnostik nach sich ziehen. Während ÖA ohne Fisteln hierbei stets auffällig werden, weist nur ungefähr jede 3. ÖA mit Fistel einen signifikant verkleinerten Magen auf. 


\section{Introduction}

$\nabla$

During the 5th to 6th week of embryonal development the oesophagus and trachea separate from a common anlage within the early intestinal tube. An incomplete separation leads to the congenital malformation of oesophageal atresia (OA). In the majority of the cases (72-90\%) the trachea is also involved in the form of a tracheo-oesophageal fistula between the lower section of the trachea and the oesophagus. The prevalence varies from region to region and is estimated to amount to an average of 2.43 to 2.86 cases per 10000 births [1-3]. A large proportion of the afflicted infants also exhibit further malformations or syndromes (such as, e.g., VACTERL association, trisomy 18, CHARGE syndrome). The most frequent associated malformation is congenital heart disease. In current reports of the EUROCAT Register only $44.7 \%$ of the cases are isolated findings [1]. Beside the associated malformations, the regular occurrence of preterm births represents a significant prognostic factor. Because of the frequent occurrence of polyhydramnios, premature delivery ensues in $38.5 \%$ of the cases $[1,4,5]$. Survival rates of almost $100 \%$ can be expected in isolated cases with adequate prenatal and neonatal management [6-8]. Later complications and morbidities during childhood consist of swallowing difficulties on account of narrow anastomoses or gastro-oesophageal reflux as well as recurring infections [9-11].

The current data situation is contradictory with regard to benefits for the afflicted babies resulting from prenatal diagnosis. Whereas, for example, Brantberg and co-workers demonstrated a significantly better survival (100 vs. $73 \%$ ) for cases identified prior to birth, other groups found a poorer prognosis for this collective $[12,13]$. The latter can be explained by the over-representation of $\mathrm{OA}$ without fistulas and associated malformations in the group of prenatally detected cases. However, current opinion is that prenatal diagnosis must be considered as a benefit in that it provides a possibility for prenatal counselling of the parents and a reduction of postpartum transfers [14].

The existing detection rates within Europe vary between less than $10 \%$ to more than $50 \%$ (on average $36.5 \%$ ) [1,15]. Sonographic visualisation of the oesophagus stretches even modern ultrasound systems to the limits of their resolution. In cases without a fistula the inability to visualise gastric filling leads to the diagnosis [16]. Cases with fistulas are not so frequently detected prenatally. Although a small stomach has been described by many groups as a sign, there is mostly a lack of an objectifiable limiting value for gastric size [13]. The aim of the present study is to examine the gastric size as a potential diagnostic criterium for foetuses with OA not only with but also without tracheo-oesophageal fistulas.

\section{Material and Methods}

\section{$\nabla$}

The underlying investigations were carried out in the Department of Prenatal Medicine of the University Hospital Tübingen and findings were assessed retrospectively.

\section{Measurement methods}

First of all the digitally saved images for gastric circumference measurements of routinely performed biometric examinations were examined. A prerequisite was the clear demonstration of the anatomic landmarks spinal column cross-section, parallel sections of rib pairs, the full stomach and the proximal part of

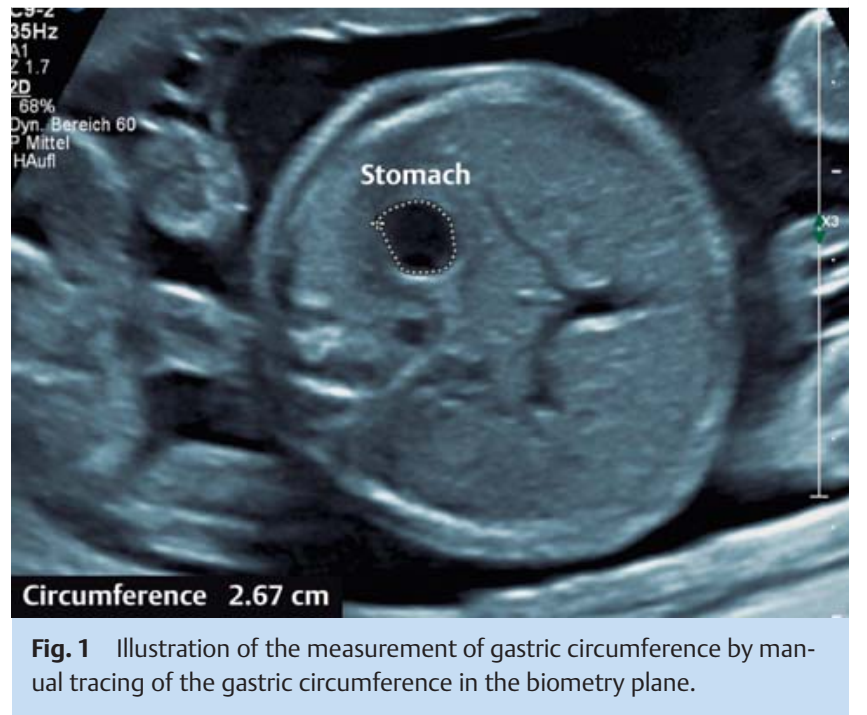

the umbilical vein and its transition to the ductus venosus and to the right portal vein. The gastric filling was always measured in the biometry plane. For this the gastric circumference was determined manually on the digitally saved images ( $\bullet$ Fig. 1 ).

\section{Collective}

To obtain an average value for the circumference, values from 374 normal singleton pregnancies were considered. The test collective consisted of 59 pregnant women in whom there was evidence for foetal OA.

In pregnancies with conspicuous foetuses the first examination undertaken in the Gynaecology Department of Tübingen University Hospital was considered in each case.

\section{Registration of associated influencing factors}

Beside the gastric circumference, we also recorded the head circumference, the abdominal circumference, the femur length as well as the gestational age at the time of the examination. Furthermore, the existance of polyhydramnios, defined as the largest vertical amniotic fluid depot over $8 \mathrm{~cm}$, as well as performance of relief drainage measures were recorded.

\section{Statistical Analysis}

In normal foetuses significant factors influencing the gastric circumference were investigated by linear regression analysis. Subsequently the gastric circumference was transformed to a $z$ value and comparisons between foetuses with OA with and without fistula and the normal population were made with the help of t tests. Differences with a $\mathrm{p}$ value $<0.05$ were considered to be significant.

The results are given as median (range) or average (standard deviation $\mathrm{SD}$ ) values.

\section{Approval of ethical committee}

Because of the retrospective anonymized character of our study, an approval of the local ethical committee was not necessary. However, the ethical committee was informed about the study (IEC number: 597/2015R). 


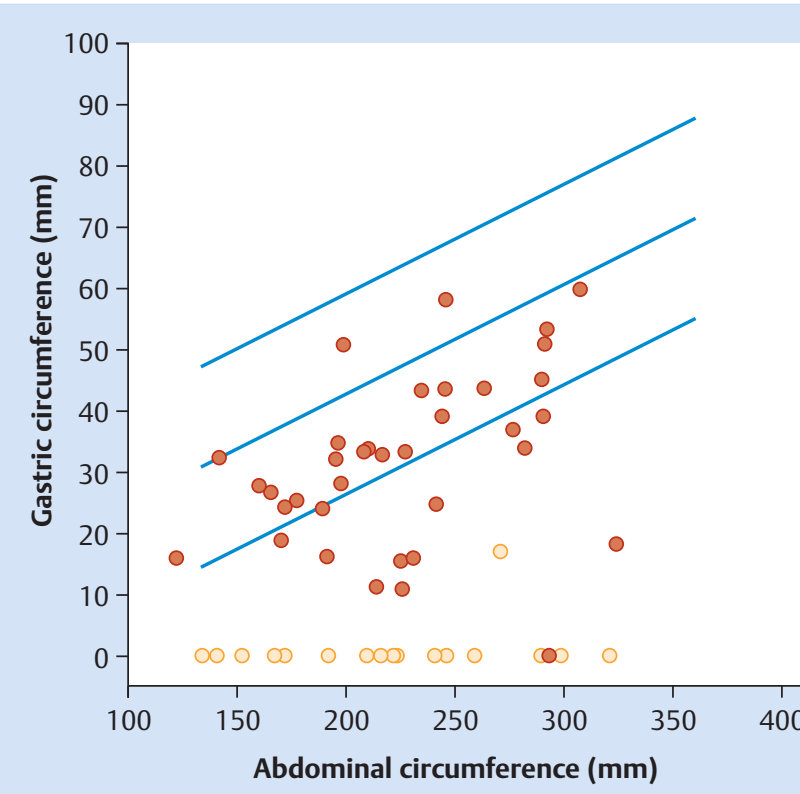

Fig. 2 Graphic presentation of the normal distribution of gastric circumference in dependence on abdominal circumference including the 5th and 95th percentiles. The points show the gastric circumference values of foetuses with $\mathrm{OA}$ (red dots with fistula, orange dots without fistula).

\section{Results}

$\nabla$

\section{Characteristics of the enrolled pregnant women}

Altogether 433 patients were included in the evaluation. The median body weight amounted to $62.3 \mathrm{~kg}$ (range $45.0-163.0 \mathrm{~kg}$ ). The median gestational age was 23.3 weeks (range 18+2-39+1 weeks) whereby 261 (60.3\%) were seen before the $26+0$ week and $172(39.7 \%)$ thereafter.

\section{Distribution of foetuses with oesophageal atresia and gastric circumference}

OA was present in $59(13.7 \%)$ of the 433 foetuses. Of these 38 (64.4\%) foetuses had OA with and 21 (35.6\%) OA without a tracheo-oesophageal fistula. Also 20 (33.9\%) of the foetuses had a chromosomal disorder, the proportions in the OA groups with and without a fistula were 23.7 and $52.4 \%$, respectively. 14 (36.8\%) of the foetuses with $\mathrm{OA}$ and a fistula also had a polyhydramnios. Among the group of foetuses with OA but without a fistula polyhydramnios was diagnosed in 12 (57.1\%) of them.

For 21 of the foetuses no stomach could be observed during the entire examination period. Of these 20 (95.2\%) had an OA without fistula. In these cases the gastric circumference was set at $0.1 \mathrm{~mm}$. The average gastric circumference in the normal group amounted to $43.0 \mathrm{~mm}$ (SD $13.7 \mathrm{~mm}$ ) and in foetuses with and without fistula to $33.8 \mathrm{~mm}$ (SD $22.7 \mathrm{~mm}$ ) and $0.9 \mathrm{~mm}$ (SD $3.7 \mathrm{~mm})$.

Association of gastric circumference with other factors In the normal foetuses there was a significant association between gastric circumference and abdominal circumference ( circumference $=6.809+0.179 \times$ abdominal circumference, $r=0.686, p<0.0001)$. In addition significant correlations with gestational age $(r=0.669, p<0.0001)$, head circumference

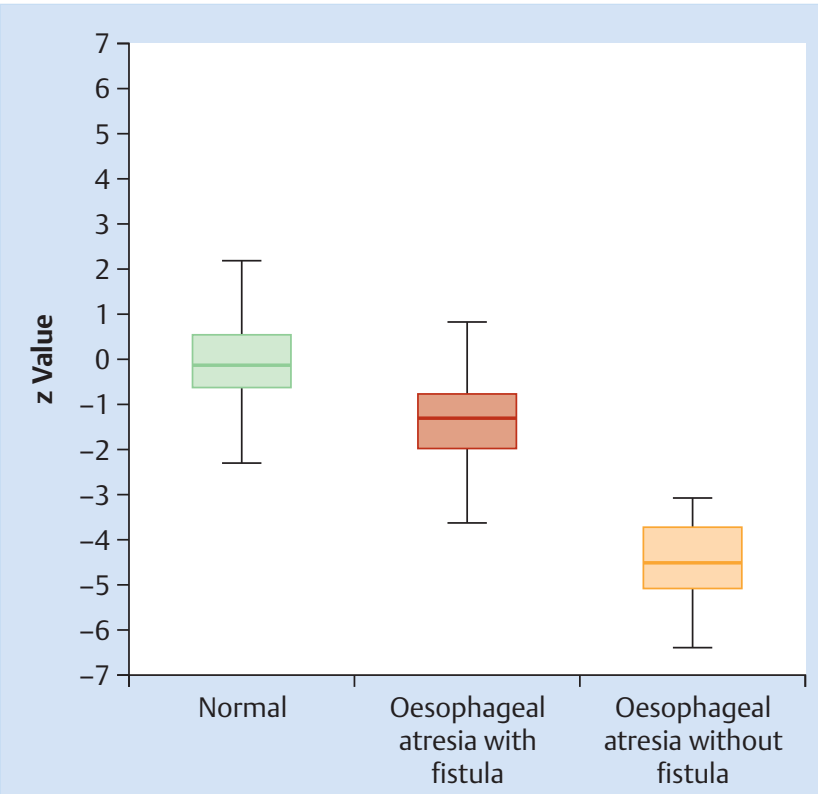

Fig. 3 Boxplots of the $z$ values for gastric circumference in the normal population, in foetuses with OA and fistulas and in foetuses with OA without fistulas. $(\mathrm{r}=0.659, \mathrm{p}<0.0001)$ and femur length $(\mathrm{r}=0.671, \mathrm{p}<0.001)$ were observed. The association with abdominal circumference was used for the further analyses.

\section{Percentile and $z$ values}

In 18 (4.8\%) of 374 normal patients the gastric circumference of the foetus was below the 5 th percentile. In contrast this was the case with 34 (57.6\%) of the foetuses with OA. In detail, there were $13(34.2 \%)$ foetuses with a fistula and $21(100 \%)$ without a fistula (๑ Fig. 2).

The average $\mathrm{z}$ values in the normal group and in the OA groups with and without fistula amounted to 0.0 (SD 1.0), -1.3 (SD 2.2) and -4.5 (SD 1,0) (t test: OA with fistula vs. normal $\mathrm{p}=0.001$; t test: OA without fistula vs. normal $p<0.001$; $t$ test: OA with fistula vs. OA without fistula $\mathrm{p}<0.0001$ ) ( $\odot$ Fig. 3).

\section{Discussion}

The present study has shown that the average gastric size, measured as gastric circumference at the level of the abdominal biometric plane is reduced not only in foetuses with OA and fistula but also in foetuses with OA but without fistula. In all cases without fistulas a completely or almost completely empty stomach was seen. The combination of a non-visualisable or very small stomach with polyhydramnios is a well known sign for the presence of an oesophageal obstruction $[15,17,18]$. However, the appreciable false positive rates and the often subjective evaluation of gastric filling need to be taken into consideration $[4,19]$. Attempts to improve the prenatal detection rates concentrate on the prenatal visualisation of the oesophageal pouch sign that occurs through dilatation of the blind-ending proximal segment of the oesophagus $[20,21]$. But, in most cases, the OA results in this pathognomic blind sack being missed due to the fistula. In addi- 
tion, the pouch sign can also be seen as a temporary transient finding in structurally inconspicuous foetuses, so that false positive findings are recorded [22].

Recognition of the majority of cases of OA with fistula represents the key problem. Impairments of foetal swallowing in such cases depend on the lumen of the tracheo-oesophageal fistula. In cases with large fistulas even the occurrence of polyhydramnios may be lacking. The sensitivity of polyhydramnios alone amounts to merely $73 \%$ in some studies [13]. In combination with the criterion of a small stomach at least a positive predictive value of up to $67 \%$ can be expected [13]. In our collective there was a comparatively low rate of polyhydramnios. Merely $36.8 \%$ of the foetuses with OA and a fistula and $57.1 \%$ of the foetuses with OA without a fistula exhibited polyhydramnios. The reason for this is to be seen in the high proportion of severe chromosomal disorders of $33.9 \%$ that in most cases led to an early termination of the pregnancy and the stronger weighting in the 2nd trimester. Polyhydramnios develops in the course of the pregnancy to an ever increasing extent and is thus mostly to be found for the first time in an obvious degree in the 3rd trimester.

In many studies the assessment of gastric filling was purely subjective. An objective measurement by means of a standardised gastric circumference appears to be more reasonable in such cases. With the present study we have shown that the gastric size in at least $36.8 \%$ of the afflicted foetuses with fistulas lies below the 5th percentile. Accordingly, the detection of a small stomach is a sign for further detailed diagnostic work-up.

The direct visualisation of the oesophagus either by means of high resolution 2D or 3D sonography or also by magnetic resonance imaging is extremely difficult and time-consuming [23, 24]. In isolated case reports, the direct prenatal demonstration has been realised by concentration on the area between the aorta and the trachea [25]. If detection of the pouch sign is successful its predictive value must be assessed as being high. In some studies the value not only for sonography but also for foetal MRI has been $100 \%$, while other studies refer to the possibility of false positive findings $[19,22,26]$. This shows that even though a detailed sonographic examination of the oesophagus is technically possible, the method cannot be applied for unselected routine screening. Measurement of the gastric size can be helpful here since the presence of a small stomach can define a risk group for which a detailed examination of the oesophagus is required.

A further improvement in the diagnostics can be expected from the use of 3D sonography [27]. However, use of the published normal values of three-dimensional biometry is at present limited due to the large discrepancies and the lack of methodological standardisation [28].

In very recent studies an approach involving biochemical analysis of the amniotic fluid has been described. Here, unchanged values with regard to L-leucine aminopeptidase (AMP) and elevated concentrations of alpha-foetoprotein (AFP) and gamma-glutamyl transpeptidase (GGT) are expected so that especially the quotient from both concentrations has exhibited very good sensitivities and specificities in the first studies (98\%/100\%) [29,30]. The currently available studies, however, are based on very small case numbers and require confirmation by larger trials. Furthermore, this is not suitable as a screening procedure due to its invasiveness and the thus associated interventional risks.

A limitation of the present study is its retrospective character and the thus associated lack of consideration of the dynamics of gastric filling. The latter are not constant and are subject to foetal swallowing cycles [31]. However, this limitation holds for all in- cluded pregnancies and thus equally for the recorded gastric sizes of the afflicted foetuses as well as those of the normal population.

\section{Practical Conclusions \\ $\nabla$}

The gastric size in foetuses with $\mathrm{OA}$ is reduced in cases with complete obstruction of the oesophagus. We have shown that reduced gastric filling below the 5th percentile is also found in $36.8 \%$ of the foetuses with tracheo-oesophageal fistulas. Accordingly the measurement of gastric size can define a risk group requiring extensive further diagnostic work-up of the oesophagus.

\section{Conflict of Interest}

$\nabla$

None.

\section{References}

1 Pedersen RN, Calzolari E, Husby S et al. Oesophageal atresia: prevalence, prenatal diagnosis and associated anomalies in 23 European regions. Arch Dis Child 2012; 97: 227-232

2 Depaepe A, Dolk H, Lechat MF. The epidemiology of tracheo-oesophageal fistula and oesophageal atresia in Europe. EUROCAT Working Group. Arch Dis Child 1993; 68: 743-748

3 Forrester MB, Merz RD. Epidemiology of oesophageal atresia and tracheo-oesophageal fistula in Hawaii, 1986-2000. Public Health 2005; 119: 483-488

4 Abele H, Starz S, Hoopmann $M$ et al. Idiopathic polyhydramnios and postnatal abnormalities. Fetal Diagn Ther 2012; 32: 251-255

5 de Jong EM, de Haan MA, Gischler SJ et al. Pre- and postnatal diagnosis and outcome of fetuses and neonates with esophageal atresia and tracheoesophageal fistula. Prenat Diagn 2010; 30: 274-279

6 Deurloo JA, Ekkelkamp S, Schoorl M et al. Esophageal atresia: Historical evolution of management and results in 371 patients. Ann Thorac Surg 2002; 73: 267-272

7 Konkin DE, O'hali WA, Webber EM et al. Outcomes in esophageal atresia and tracheoesophageal fistula. J Pediatr Surg 2003; 38: 1726-1729

8 Lilja HE, Wester T. Outcome in neonates with esophageal atresia treated over the last 20 years. Pediatr Surg Int 2008; 24: 531-536

9 Little DC, Rescorla FJ, Grosfeld JL et al. Long-term analysis of children with esophageal atresia and tracheoesophageal fistula. J Pediatr Surg 2003; 38: 852-856

10 Chetcuti P, Phelan PD. Gastrointestinal morbidity and growth after repair of oesophageal atresia and tracheo-oesophageal fistula. Arch Dis Child 1993; 68: 163-166

11 Chetcuti P, Phelan PD. Respiratory morbidity after repair of oesophageal atresia and tracheo-oesophageal fistula. Arch Dis Child 1993; 68: 167170

12 Brantberg A, Blaas HG, Haugen SE et al. Esophageal obstruction-prenatal detection rate and outcome. Ultrasound Obstet Gynecol 2007; 30: 180-187

13 Kunisaki SM, Bruch SW, Hirschl RB et al. The diagnosis of fetal esophageal atresia and its implications on perinatal outcome. Pediatr Surg Int 2014; 30: 971-977

14 Garabedian C, Sfeir R, Langlois C et al. Does prenatal diagnosis modify neonatal treatment and early outcome of children with esophageal atresia? Am J Obstet Gynecol 2015; 212: 340.e1-340.e7

15 Houben CH, Curry JI. Current status of prenatal diagnosis, operative management and outcome of esophageal atresia/tracheo-esophageal fistula. Prenat Diagn 2008; 28: 667-675

16 Sase M, Asada H, Okuda $M$ et al. Fetal gastric size in normal and abnormal pregnancies. Ultrasound Obstet Gynecol 2002; 19: 467-470

17 Choudhry M, Boyd PA, Chamberlain PF et al. Prenatal diagnosis of tracheo-oesophageal fistula and oesophageal atresia. Prenat Diagn 2007; 27: 608-610

18 Stringer MD, McKenna KM, Goldstein RB et al. Prenatal diagnosis of esophageal atresia. J Pediatr Surg 1995; 30: 1258-1263 
19 Ethun CG, Fallon SC, Cassady CI et al. Fetal MRI improves diagnostic accuracy in patients referred to a fetal center for suspected esophageal atresia. J Pediatr Surg 2014; 49: 712-715

20 Kalache KD, Wauer R, Mau H et al. Prognostic significance of the pouch sign in fetuses with prenatally diagnosed esophageal atresia. Am J Obstet Gynecol 2000; 182: 978-981

21 Yagel S, Sonigo P, Rousseau V et al. Esophageal atresia diagnosed with three-dimensional ultrasonography. Ultrasound Obstet Gynecol 2005; 26: 307-308

22 Solt I, Rotmensch S, Bronshtein M. The esophageal "pouch sign": a benign transient finding. Prenat Diagn 2010; 30: 845-848

23 Brugger $P C$, Weber $M$, Prayer D. Magnetic resonance imaging of the normal fetal esophagus. Ultrasound Obstet Gynecol 2011; 38: 568-574

24 Malinger G, Levine A, Rotmensch S. The fetal esophagus: anatomical and physiological ultrasonographic characterization using a high-resolution linear transducer. Ultrasound Obstet Gynecol 2004; 24: 500-505

25 Develay-Morice J-E, Rathat G, Duyme M et al. Ultrasonography of fetal esophagus: healthy appearance and prenatal diagnosis of a case of esophagus atresia with esotracheal fistula. Gynecol Obstet Fertil 2007; 35: 249-257
26 Garabedian C, Verpillat P, Czerkiewicz I et al. Does a combination of ultrasound, MRI, and biochemical amniotic fluid analysis improve prenatal diagnosis of esophageal atresia? Prenat Diagn 2014; 34: 839-842

27 Kusanovic JP, Nien JK, Gonçalves LF et al. The use of inversion mode and 3D manual segmentation in volume measurement of fetal fluid-filled structures: comparison with Virtual Organ Computer-aided AnaLysis (VOCAL). Ultrasound Obstet Gynecol 2008; 31: 177-186

28 Ioannou C, Sarris I, Salomon LJ et al. A review of fetal volumetry: the need for standardization and definitions in measurement methodology. Ultrasound Obstet Gynecol 2011; 38: 613-619

29 Czerkiewicz I, Dreux S, Beckmezian A et al. Biochemical amniotic fluid pattern for prenatal diagnosis of esophageal atresia. Pediatr Res 2011; 70: 199-202

30 Muller C, Czerkiewicz I, Guimiot F et al. Specific biochemical amniotic fluid pattern of fetal isolated esophageal atresia. Pediatr Res 2013; 74: 601-605

31 Sase M, Miwa I, Sumie M et al. Gastric emptying cycles in the human fetus. Am J Obstet Gynecol 2005; 193: 1000-1004 